\title{
Are instructivist pedagogies more appropriate for learning the sciences in South African low-quintile schools than western literature suggests?
}

\section{Angela Elisabeth Stott}

University of the Free State South Campus

stottae@ufs.ac.za

[Received 5 Dec 2017; accepted:1 May 2018)

\begin{abstract}
Some research suggests that the use of instructivist teaching strategies may be detrimental to learning while other research asserts that such strategies can enhance learning under certain conditions. In this article I make the argument that the conditions present in South African low-quintile 1-3 schools, and, probably, more broadly in schools typical of developing countries, make such strategies appropriate and may indeed be the only strategies currently implementable on a large scale in the South African low-quintile school context. I propose two kinds of instructivist resources, low-language-demand drill-and-practise worksheets and software, that may be effective in improving learning in this context by developing language competence, increasing feedback and reinforcement, and extending teaching and learning time. I caution against a simplistic interpretation of the argument, and discuss possible difficulties. Discussions such as this are necessary in our search for appropriate and implementable solutions to the crisis of South African underperformance in education.
\end{abstract}

Keywords: developing countries, Information and Communication Technologies (ICT), instructivism, elearning, formalism, science learning, South African low quintile schools

\section{Introduction}

South Africa has a bimodal education system (Spaull, 2013). Learners who attend schools serving the richest $25 \%$ of the population (quintile 5 and some quintile 4 schools) perform close to international averages. The remaining $75 \%$ (learners in quintile 1-3 and some quintile 4 schools) perform at or near the bottom on international Science and Mathematics benchmarking tests (Spaull \& Kotze, 2015) and show very low levels of general skills, including numeracy and literacy (Pretorius \& Spaull, 2016). Despite numerous interventions and considerable amounts of money being channelled into improving this situation, there has been little large-scale improvement (Bayat, Louw, \& Rena, 2014), and, possibly, decline, rather (Graven, 2014). While little is known about how to improve the situation, it appears that the factors correlated to academic achievement are not the same for the richest $25 \%$ and the poorest $75 \%$ of South African learners (Spaull, 2013). However, most of the existing 
literature about interventions aimed at promoting learning report on studies conducted in developed countries that experience conditions similar to those of the top $25 \%$ of South African schools.

Obstacles to progress in the context of learners learning the sciences in low-quintile South African schools include a poor command of the language of learning and teaching (LOLT) (Pretorius, 2015); low levels of prior knowledge and skill of learners and teachers; a general attitude of apathy; and inefficient use of time (Van der Berg, Spaull, Wills, Gustafsson, \& Kotzé, 2016). This article contributes to the search for possibilities which may be implementable in the South African low-quintile school context given these problems, and possible amelioration of them.

\section{Problem statement}

While both instructivist and constructivist pedagogies may be consistent with a constructivist view of learning (Ausubel, Novak, \& Hanesian, 1986), they differ in their views of how to best promote construction of learning. Instructivists view pedagogy that reduces extraneous cognitive load as far as possible, provides repeated practice to attain mastery, and gives immediate feedback, as being the most effective and efficient (Klahr, 2009). Such a view is embedded in cognitive psychology that extends the stimulus-response approach of behaviourism to include models of what happens within the brain during learning (Mayer, 2009). Teacher-centred, formalistic, drill-and-practise pedagogy is consistent with instructivism (Niederhauser \& Stoddart, 2001). Constructivists, in contrast, believe that deliberately introducing cognitive load and withholding feedback can enhance motivation and depth of learning, thus leading to the longer retention of knowledge (Wise \& O'Neill, 2009). This may, for example, be done by embedding learning within authentic contexts, such as in problem-based learning (Savery, 2006), and using other learner-centred, progressive pedagogies.

Cronjé (2007) describes the international historical pendulum swing between instructivist and constructivist pedagogies. South Africa's education history since 1994 (Chisholm, Motala, \& Vally, 2003; Hoadley, 2018) provides an excellent example of this, with my own experiences having some correspondence to our national changes. Snippets of this personal story are relevant to this discussion since they illustrate and contextualise the argument I make in this article.

In 1980 my father brought one of the first personal computers, with all of eight kilobytes of RAM, into South Africa. The software he programmed included a highly rigorous drill-andpractise quiz generator created to help my brother and me with our school work. While my marks rose as a result, the repetitiveness and unrelenting requirement for exactness frustrated my brother, inducing avoidance behaviour. Consistent with our differing experiences, research on the effectiveness of the use of computers in education has yielded widely different conclusions. Burns and Ungerleider (2003), in their review of northern and western literature about Information and Communication Technologies (ICT) usage, report much 
success for the promotion of learning using ICT, but also cite studies suggesting that some ICT, particularly drill-and-practise software, may retard learning.

Thanks, largely, to an immense amount of drill-and-practise exam-training, I topped the Department of Education and Training (DET) matriculation list in 1990, receiving considerable media attention since, as a white learner in a mainly black school in apartheid South Africa, I had crossed the racial divide. Despite the fact that in some cases my understanding was very limited, enough practice had made me proficient at answering questions as required. The accolades I received suggested to me, at the time, that this was sufficient. The very next year I began my teaching career in the same well-managed rural mission school in KwaZulu-Natal from which I had matriculated, while pursuing a degree through correspondence. My early years of physical, natural, and life sciences teaching were characterised by strong instructivist pedagogy. However, I became increasingly exasperated by my learners' surface approach to learning, low intrinsic motivation, and the meaninglessness of repetition without understanding. In addition, I embarked on an exciting personal pursuit of deep understanding of science concepts, which convinced me of the hollowness of superficial exam training.

I was therefore more than ready for South Africa's swing towards constructivist pedagogy with the introduction of outcomes-based education in the early 2000s. Together with the rest of our country's teaching population, I sat through poorly delivered teacher training workshops that vilified the rigid, individualistic, rote drill-and-practise of the past, and painted the bright new possibilities of open-ended questioning and collaborative group work that promote deep learning and develop twenty-first century skills. These workshops evoked a general aversion to the new system and its pedagogies in my colleagues - a view shown to have been wide-spread (Chisholm, 2000). But, for me they coincided with my enrolment in a Master's programme, and subsequently a $\mathrm{PhD}$ in Science Education, which provided a solid conceptual base regarding the advantages of constructivist pedagogy. Nevertheless, my conversion of this theory into practice was fraught with difficulties. Some of these, as well as my own pendulum swings in search of an appropriate balance along the pedagogical continuum, are documented in Stott (2008) and Stott and Hobden (2008).

However, the sense of arrival achieved through this process was quickly dispelled in my move to the mentorship of science teachers in townships over the past four years. This has brought me into daily contact with the extremely low knowledge and skill levels of the majority of our country's learners, overcrowded classroom conditions, low content knowledge of the teachers in general, and the state of dysfunctionality of the schools. I have never seen any of the teachers or teacher-educators with whom I work using constructivist teaching strategies in this environment. Some of these teachers are able to inspire considerable numbers of their learners out of the pervasive apathy characteristic of their environment and guide them to reasonable achievement. However, when I evaluate their teaching in terms of western literature, such as Knight et al. (2015), I cannot acknowledge their skill, since they teach in a completely instructivist manner with strong behaviourist elements. Similarly, I find that the kinds of resources which these teachers use to apparent 
effect may be considered harmful when evaluated in terms of western literature, such as that by Burns and Ungerleider (2003). Therefore, I experience a tension between what seems to be effective in low-quintile schools and what I believe to be good teaching based on the literature and my own teaching in a stable, well-managed environment. This tension has made me pose the question: Are instructivist pedagogies more appropriate for learning the sciences in South African low-quintile schools than western literature suggests?

In this article I argue that the existing literature supports the use of both constructivist and instructivist pedagogies in all contexts, but that both the limited empirical evidence available and the arguments embedded in a collection of learning theories support a view that instructivist pedagogies are more appropriate for learning the sciences in South African lowquintile classrooms than western literature suggests. Although the arguments made are seen to be consistent with those given in relation to five of Hugo and Wedekind's (2013) six pedagogical fallacies regarding optimal pedagogy for the poor, I argue that what they term the formalisation first fallacy is not a fallacy at all. Their theoretical motivation against the placement of formalism as the necessary starting point in the evolution of quality education in developing countries, is compelling. However, in practise, I contend, it does seem to be necessary, as Beeby (1966) found, to start with a focus on formalism, also termed instructivism (Guthrie, 2018).

As mentioned above, I propose particular types of instructivist resources as being potentially beneficial in the context of learners in South African low-quintile schools learning the sciences-low-language-demand drill-and-practise worksheets and software. This proposal emerges from my own experience, as well as from my reflection on the existing literature expounded here. This argument is probably generalisable to learning of any subject in classrooms typical of developing countries.

\section{Conceptual and theoretical framework}

Commentators on the instructivist-constructivist continuum, also referred to as the formalistic-progressive or teacher-centred-learner-centred continuum, such as Cronjé (2007), Hugo and Wedekind (2013) and Schweisfurth (2013), call for a cessation of the simplistic view that instructivism and constructivism are diametrically opposed, and suggest, rather, that each pedagogy that lies on the continuum between the extremes should be selected for use according to the context and required outcomes. The value of the employment of a wide range of pedagogy can be understood if we acknowledge the values of both acquiry and participatory models of learning, each of which has strengths and weaknesses for describing and explaining the complexity of learning. The issue that does need further discussion, as Wise and O'Neill (2009) have observed is this: In which conditions is each pedagogy more appropriate and implementable in an effective manner? 


\section{Learning models and associated pedagogy}

The information processing model of learning (IPM) is an example of an acquiry model of learning since it focuses on the conditions necessary to help learners acquire knowledge by effective management of the limited space of working memory. This involves the reduction of extraneous cognitive load and emphasises ways of presenting information as clearly as possible so as to harness learners' use of essential and generative cognitive processing to appropriately select and integrate knowledge elements to lead to both recall and understanding (Mayer, 2009). This is very different to situative learning theory, which is an example of a participatory model of learning since it focuses on socialisation into the domain as learners pursue their own goals while participating in sense-making activities within a community of practice (Wenger, 1999). This leads to the development of identity, purpose, and motivation through social interaction with the complexity of knowledge embedded in authentic contexts (Mattar, 2018).

It is difficult, and also meaningless (Wise \& O'Neill, 2009) to compare the relative merits of constructivist and instructivist pedagogies. However, it is also dishonest to compare poor instructivist teaching with idealised constructivist teaching, the apparent fallacy underlying the argument that the underachievement of learners in South African low-quintile schools results from the prevalence of instructivist, and the absence of constructivist pedagogy. Such a view is clearly fallacious given evidence of high achievement associated with skilful instructivist pedagogy in the South African low-quintile context (Christie, Butler, \& Potterton, 2007; Jansen \& Blank, 2014; Malcolm, Keane, Hoohlo, Kgaka, \& Ovens, 2000), as well as in other contexts, such as the highly instructivist Knowledge is Power Program (KIPP) schools in the USA (Cheng, Hitt, Kisida, \& Mills, 2017).

The small amount of relevant empirical work available in the South African low-quintile context (e.g., Christie et al., 2007; Malcolm et al., 2000) suggests that schools that succeed, despite serving learners from low socioeconomic backgrounds, use exemplary traditional chalk and talk teaching. Of course, these findings say nothing about the results had constructivist pedagogies been employed skilfully in these contexts. Moreover, constructivists have never denied the strength of instructivism at raising learners' marks but have questioned only how meaningful this is (Wise \& O'Neill, 2009). However, these results do lend empirical support to the argument based on the implementability of skilful instructivism in the low-quintile school context and the possibility of such pedagogies leading to some form of learning gain in a context where this is extremely difficult to achieve (Bayat et al., 2014). Until similar empirical support is available for the skilful implementation of constructivism in the South African low-quintile school context, we are left with the impression that instructivism is more appropriate in this context than western literature suggests. 


\section{Support for an instructivist focus in the South African low- quintile school context}

In this article I argue that, in general, in the South African low-quintile school context, situated learning theory and associated constructivist pedagogy are luxuries we are sadly not yet ready to implement on a large scale. Further, I take the view that a focus on constructivist pedagogy is appropriate in contexts where learners perform at least moderately well in the classroom setting, or where highly-skilled teachers with strong content knowledge and experience in implementation of constructivist pedagogy teach learners of any kind. In such contexts exploring ways to enhance knowledge transfer to more complex settings is likely to be feasible. In the typical South African low-quintile context, where rates of passing on merit in grades 8-11 may be $20 \%$ or lower (Branson, Hofmeyr, \& Lam, 2014) and teachers are often not familiar with the content knowledge (Van der Berg et al., 2016), we first face the challenge of helping learners to recall knowledge and become able to perform routine operations stipulated by the curriculum (Stott, 2017; Van der Berg et al., 2016).

I present three reasons to support this view. First, constructivist pedagogies are very difficult to implement (Schweisfurth, 2013). This is the case even in typical western classrooms which are well-resourced, have relatively small numbers of relatively articulate learners with reasonable levels of prior-knowledge, teachers with strong content knowledge, and a less authoritarian culture that encourages critical dialogue between teachers and learners. South African low-quintile schools typically lack all these features (Hoadley, 2018). One of the reasons for the greater implementation of instructivist pedagogies is that they are timeefficient (Klahr, 2009), a much-needed feature in South African low-quintile schools where the time available for learning and teaching is severely reduced by school dysfunctionality (Van der Berg et al., 2016). In addition, the social, epistemological, and pedagogical culture present in South African low-quintile schools and, more broadly, in the majority of subSaharan African schools, is authoritarian in nature (Cooper, 2015; Tabulawa, 2013), with instructivist pedagogies predominating (Hoadley, 2018), making the adoption of skilful instructivist pedagogies more likely to lie within the zones of proximal development of the learners and implementation of the teachers (McKenney, 2013; Tabulawa, 2013), than the adoption of skilful constructivist pedagogies would be.

Second, learners with low levels of prior knowledge and reading comprehension skills, such as the majority of those attending South African low-quintile schools (Pretorius \& Spaull, 2016), experience the limitation imposed by the small size of working memory to a greater extent than other learners (Tobias, 2009). Instructivist pedagogies help learners to manage effectively the limited size of working memory during the learning process (Fletcher, 2009). They may also help reduce the limitation working memory imposes for future learning by helping learners to automate some knowledge, thus freeing up space in working memory for new learning (Sweller, 2009).

Third, learners in low-quintile South African schools perform poorly even in questions requiring the recall of science knowledge in well-structured domains (Stott, 2017; Van der 
Berg et al., 2016), which instructivist pedagogies are highly appropriate for addressing (De Villiers, 2007). Such an argument assumes that a knowledge classification system such as Bloom's Taxonomy (Anderson \& Sosniak, 1994), is subsumptive and sequential in nature for a particular area of knowledge. This view has some empirical support (Seddon, 1978), but is also contested (Resnick, 1987), thus opening up the possibility that in the right environment a more constructivist approach may be more effective at developing learning even of lower levels of knowledge. However, it would probably be extremely difficult to turn an overcrowded, under-resourced, low-quintile classroom into such an environment.

\section{Education in developing world contexts}

The argument is made, above, that although the complexity of learning requires the employment of multiple learning theories and multiple pedagogies, in contexts of low levels of learner and teacher skill and knowledge such as those that characterise the majority of South African low-quintile schools and the classrooms of developing countries, a greater use of instructivist pedagogy is more appropriate than is the case in the kinds of classrooms more typical of western contexts.

This corresponds to what Johnson, Monk, and Hodges (2000) see as the selection (environmental pressure) view that different strategies are needed to support effectively most of the teachers working in low-quintile schools than has been reported to be effective in literature from developed countries. These authors liken the environment in South African low-quintile schools to that of a desert where few pedagogies can survive, as opposed to the tropical rainforest of the classrooms found in developed countries. They refer to a four-stage model of teacher development, rooted in Beeby's (1966) work, with most of South African low-quintile teachers falling into the first two stages, unskilled and mechanical.

Further, the individualisation of learner-centred pedagogy, together with its constructivist epistemology, is mismatched to the communal culture and strong authoritarian social structures and epistemology prevalent in developing countries (Tabulawa, 2013). It is therefore unsurprising that the implementation of learner-centred, progressive, constructivist pedagogies has failed in developing country classrooms (Guthrie, 2017; Schweisfurth, 2013) despite considerable attempts by aid agencies and policy-makers to enforce the adoption of such pedagogies (Tabulawa, 2003). Authorities such as Tabulawa (2013) and Guthrie (2018) go so far as to view constructivist pedagogies as inappropriate in developing countries.

Tabulawa argues that the popularity of constructivist pedagogies among academics, funders, and politicians is ideological and political rather than being founded on empirical research into comparative learning effectiveness. He urges his readers "to question the desirability of constructivist, learner-centred pedagogy in Third World contexts, given its colonising and hegemonic tendencies" (2013, p. xxii). In contrast, these very ideals, which include the promotion of critical thinking and democratisation, were embraced by the post-apartheid curriculum writers in South Africa so as to "transform South African society" because of "a need to address the legacy of apartheid" (Department of Education, 2003, p. 2). Despite this 
ideological rhetoric, however, over 20 years after the fall of apartheid, teacher-directed rote and surface learning and collective chanting dominate the South African low-quintile classroom (Hoadley, 2018). The colossal failure of outcomes based education in South Africa is consistent with Schweisfurth's conclusion, based on a meta-analysis of attempts to implement learner-centred education (LCE) in developing country contexts, that "the history of the implementation of LCE is riddled with stories of failures grand and small" (Schweisfurth, 2011, p. 425).

This undisputed failure of constructivist pedagogies, in the main, in the developing world has led Guthrie (2018) to oppose the use of such pedagogies in such contexts; he warns that "progressives can be caged in a cosmology of cumulative hallucination where errors compound, leading to a vicious circle of misinformation for continuing the irrational pursuit of the unattainable" (p. xvi). In contrast, Schweisfurth sees the value of the ideologies of learner-centred pedagogies worthy of encouraging persistence since "human rights arguments rise above these questions of evidence" (2013, p. 5). Her proposed solution includes a focus on culturally-relevant learning-centred pedagogies and essential dimensions of quality education which are attainable even when a teacher-dominated, instructivist pedagogy is employed (Lattimer, 2015).

In a similar attempt to find pedagogical principles that are generalizable across social and cultural contexts, Todd and Mason's (2005) review of the literature revealed that learner performance is enhanced in any context by the provision of feedback and reinforcement and by increasing time for teaching and learning. It is obvious that there is a need for improvement in these areas in the context of South African low-quintile schools where a productive rhythm of effective time-management is largely absent (Van der Berg et al., 2016). Effective solutions to the observed severe underperformance have to be time-efficient, provide the structure needed to encourage more effective time-management, feedback, and reinforcement, and provide practical ways to extend learning and, if possible, teaching time. They also have to address the poor language competence of the learners. The use of particular kinds of teaching and learning support material, mentioned above, that are consistent within this framework are again proposed-low-language-demand drill-and-practise worksheets and software.

\section{Low-language-demand drill-and-practise resources}

In this article low-language-demand worksheets and software refer to resources that support the acquisition of language and concepts without expecting users to be already proficient in the use of the language. Drill-and-practise software refers to software that requires users to input answers that have a definite right or wrong status. The software provides immediate feedback to the user's response, including rewards or corrective punishment (De Villiers, 2007). A printed, non-interactive equivalent of such software is a drill-and-practise worksheet. 
Authorities on the role of language and literacy in science education, such as Wellington and Osborne, state that "one of the major difficulties in learning science is learning the language of science . . . attention to language is one of the most important acts that can be done to improve the quality of science education" (2001, p. 1). Proficiency in LOLT, usually English, is one of the major obstacles to progress in the South African low-quintile context (Pretorius, 2015). Vocabulary acquisition, the first step towards language competence, requires repetition (Chukharev-Hudilainen \& Klepikova, 2016), suggesting that drill-and-practise worksheets and software are appropriate ways to support the acquisition of the vocabulary foundational to the learning of science concepts.

Conceptual understanding is embedded in language (Konicek-Moran \& Keeley, 2015) and this language tends to be complex and sophisticated for science concepts. It is possible, by using appropriate scaffolding, to help learners with low LOLT abilities to develop levels of understanding which might otherwise be considered beyond their reach (Stott, 2008). Lowlanguage-demand worksheets and software provide a highly structured form of such scaffolding. The kinds of low-language-demand resources envisioned as being useful in the South African low-quintile context have sections that are aimed at drilling necessary vocabulary, developing understanding of scientific concepts, and developing competence in algorithmic manipulation. One format in which this can be done is by the use of gap-fill worksheets. In their electronic format, these are gap-fill quizzes.

Gap-fill (also called cloze-procedure) questions, have mixed appraisals on their value. Jongsma (1971), in a review of the relevant literature available at the time, found no convincing evidence for the enhancement of learning through use of cloze-procedures. More recently, O'Toole and Schefter (2008) found that language-conscious approaches to science teaching, including the use of cloze-procedures, were beneficial for learners of a variety of levels of English language competence. Lidbury and Zhang (2008) found that a languagefocused intervention, including the use of electronic cloze-procedures, improved the test scores of the higher achieving English foreign language molecular biology university students involved in their study and improved the self-reported reading and language confidence of the students of all achievement levels.

Highly structured low-language-demand drill-and-practise worksheets are likely to meet the criteria laid out in the conceptual framework above. Their highly instructivist nature and lowlanguage demand make them time-efficient. The security they offer to a teacher should increase the likelihood that he or she will be empowered to complete the curriculum which, in this context, is rare and is associated with enhanced learner performance (Van der Berg et al., 2016). Furthermore, such worksheets should increase the likelihood of teachers being in class, rather than missing lessons as a strategy to avoid having to teach topics they feel illequipped to teach (Van der Berg et al., 2016). They should also enhance learning time because of increasing the likelihood that learners will engage with the worksheets for homework, given their attainability.

Where it is possible to support learning further by the use of corresponding software, feedback, reinforcement, learning, and virtual teaching time can be further increased without 
burdening the teacher with excessive extra lessons. The extent of the learning backlog present among almost all South African learners in low-quintile schools is so great that an enormous amount of extended learning time and additional feedback and reinforcement is needed to bring these learners up to par with their more privileged peers. It is impossible for all this extra learning time, feedback, and reinforcement to be provided by the teacher.

\section{A caution to avoid political semantic side-tracking}

I interpret the call for a shift of "focus from a discourse of deficit and helplessness towards a discourse of possibilities in the struggle for equity and quality for all" (Graven, 2014, p. 1) to refer to a movement away from dwelling on the problems present in our context to one in which we focus on solutions, while still acknowledging the existence of the problems. I hold that appropriate solutions cannot be obtained without acknowledging the problems that the solutions need to address. This includes the acknowledgement of the existence of deficit, such as the firmly established fact of the low skill and knowledge levels of the vast majority of the learners and many of the teachers in South African low-quintile schools (Van der Berg et al., 2016). Of course, this view of deficit is restricted to the kinds of skill and knowledge valued in the curriculum. It is expected that some exception may be taken to such a view, such as that expressed by Zipin (2013) in his rebuttal of Hugo and Wedekind's (2013) argument that teaching and learning may be largely absent in classrooms in developing countries and therefore the establishment of a minimal pedagogy is the first priority in such a context. Zipin's call for debate concerning the kinds of knowledge which should be valued is seen as a separate issue. Instead of being side-tracked by politically correct semantics or debates on the acceptability of the standards currently valued by our education authorities, I focus, in this article, on the acquisition of solutions that are appropriate to our particular context at this time.

\section{Envisioned difficulties}

In my experience, the provision of low-language-demand drill-and-practise worksheets is greatly welcomed by teachers, with adoption mainly limited by access to photocopying facilities. The problems envisioned regarding the use of such worksheets are mainly restricted to inappropriate use which may lead to sub-optimal or detrimental usage. These concerns are addressed later in the article.

Adoption of corresponding software will, in my experience, be low unless appropriate external technical, logistical, and motivational support is provided. A lack of access to computers remains a barrier despite many low-quintile schools having received donations of computers for learner-use, and sometimes, in my experience, having multiple computer centres which can rival those of the wealthiest schools in the country, but which remain locked up. Software that runs on mobile devices has a greater chance of learner-use, given the more ubiquitous nature of such devices among learners themselves, even in contexts of poverty. 
While South African teachers tend to have positive attitudes towards the use of ICTs for improving the effectiveness of learning and teaching, they have low perceptions of their control over the actual use of ICT in their teaching, particularly regarding getting learners to engage with software (Stott, 2018). The reasons for this include technical problems and a lack of confidence at trouble-shooting these, high syllabus pressures, and a lack of access to computers for subject use. Additionally, in my experience, many learners in low-quintile schools have had little to no prior exposure to computer use and so need help with basic skills. Furthermore, many of the learners have such poor English speaking and reading abilities that they find engagement even with low-language-demand software difficult. These factors tend to make engagement with software slow, particularly initially. Unlike the ability of a teacher to move on with a crowded curriculum despite little learning occurring, software restricts progression until some level of mastery has been attained. While this is one of the pedagogical strengths of the software, it does create obvious logistical difficulties which could cause avoidance behaviour by the teachers.

Despite these difficulties, in my experience in working in South African low-quintile schools in Botshabelo and ThabaNchu, it is possible to achieve adoption of drill-and-practise software out of school hours for some learners, with some positive results (Stott, 2017). Continued research into such use is currently underway, with positive preliminary findings. In a context in which any intervention is difficult and many interventions seem to yield few or no learning gains (Bayat et al., 2014), it seems that this possibility should be pursued further.

\section{Caution against simplistic interpretation}

The arguments made may imply that in the South African low-quintile context, instructivist pedagogies are the only pedagogies suitable; that drill-and-practise exam-training, devoid of an emphasis on understanding and focusing only on lower order thinking skills, is the most appropriate pedagogy; that the drill-and-practise resources referred to are incorruptible and should replace all other resources; and that these views should be generalised to South African education as a whole. These are simplistic interpretations that must be refuted.

First, although it seems that in the South African low-quintile school context it is most appropriate to choose teaching strategies that lie on the instructivist side of the pedagogical continuum for a greater proportion of the time than in many other contexts, this does not mean that the use of strategies further on the constructivist side of the spectrum are never appropriate in this context. For example, the motivational benefits of embedding learning in real-life, complex contexts and the importance of development of twenty-first century skills through opportunities to collaborate, communicate, and think critically apply to low-quintile learners just as they do to learners from more privileged contexts. Nevertheless, the low prior-knowledge and skill levels of these learners make attainment of such lofty outcomes unlikely in the time-frames available to them and require even more skilled scaffolding by teachers than is needed in other contexts. 
I have done research (as yet unpublished) on two formats in which it was possible for a few low-quintile learners to achieve these outcomes to some extent. These are extracurricular voluntary participation in the Expo for Young Scientists science fair, and an inquiry-based holiday programme. Both of these required a large amount of skilled input and considerable funding. Programmes such as these are clearly important, but they require too much time, and money, and too many already scarce skills to be implemented on a large scale. The argument is therefore made that teacher-educators should model continually and provide support for some constructivist pedagogical practices in the low-quintile context, including voluntary extracurricular programmes. However, the expectations set by much of the western literature about general day-to-day pedagogy should be appropriately modified for the South African low-quintile context.

Second, it seems possible to create thinking-intensive, although heavily guided, worksheets with a low-language demand that focus on the development of understanding as well as recall. This will probably not be as effective at developing deep understanding as more openended, complex, and high-language-demand resources would be, if the latter provide attainable outcomes. However, the likelihood of achieving attainable outcomes with openended resources is probably low in typical South African low-quintile schools, given the constraints discussed above.

Third, the dangers of misusing the kinds of resources argued for in this article must be acknowledged. In the software context, such misuse is referred to by Muldner, Burleson, Van de Sande, and VanLehn (2011) as efforts to game the system, which means making progress without having to engage in the thinking that the activity is intended to elicit. Another danger is what Carey (2014) refers to as the fluency illusion-a superficial proficiency that creates a false sense of competence, hindering engagement in deeper learning. The extents to which these dangers are realised should be researched empirically for valid claims to be made. This said, it is expected that the current situation is so bad, with so little learning occurring, and so apathetic an approach to learning being prevalent, that the learners who would be prone to falling prey to these dangers would not learn less than they currently do.

Similarly, although drill-and-practise methods that target the development of automated recall may be criticised for encouraging surface and achievement, as opposed to deep, approaches to learning, this may not be entirely negative if the alternative is the apathetical approach that is currently prevalent. Besides, surface and achievement approaches to learning do have their place within the learning spectrum and appear to be the most effective and appropriate methods of learning in some contexts (Beattie IV, Collins, \& McInnes, 1997).

Fourth, it is important to caution against a view that low-quintile learners are incapable of engagement in higher order thinking and that teachers in these contexts should not employ pedagogies that aim to develop such thinking. On the contrary, I take the view that pedagogies that develop higher order thinking are important in every context, including that of the low-quintile school. It seems, however, that the feasible route to achieving this is a high emphasis on the development of basic skills and knowledge, while also trying as much as possible to develop higher order thinking and deep understanding. 
Finally, low-language-demand drill-and-practise worksheets and software are not proposed as the only type of resource to be used in the South African low-quintile context, and particularly not in the broader South African landscape. To do so would be to commit what Hugo and Wedekind (2013) call the extensional fallacy. I think that multiple resources and multiple pedagogies should be used wherever possible to mitigate the weaknesses of any one of these. Teachers and learners should be encouraged to use text-books and answer openended questions with higher language demand, as well as the kinds of resources argued for here, provided that constraints of time, and learner- and teacher-prior knowledge and skill are not prohibitive.

\section{Limitations, implications, and suggestions for research}

The greatest weakness in the argument made in this article is the lack of empirical research into the large-scale implementability of the software proposed, and the extent to which learners and teachers are likely to avoid the dangers, discussed above, which these types of resources present. My limited published (Stott, 2017), and continuing, but not yet published, empirical research into the small to medium-scale implementation of after-school softwareengagement suggests that this is feasible with appropriate support and motivation. Personal, unpublished observation also suggests to me that these types of resources are effective teacher-education tools that empower teachers to teach better, leading to empowering learners to learn better, all of which results in learners avoiding superficial engagement tricks to game the system. These observations need to be researched more fully, however, before they can be presented as claims.

It should be pointed out that a simplified form of the argument made in this article, which denies any applicability of more constructivist pedagogies and attempts to develop higher order thinking, is already held by the majority of South African teachers teaching in lowquintile schools and those who support teachers in this context. Those practitioners, like me, who also function in an academic realm, experience the tension created by a mismatch of the literature and what appears optimal and feasible in practice in this context. While such a tension can be effective in pointing to where we should surely be headed, it creates a frustrating sense of the literature being out-of-touch with the reality of the South African lowquintile school context. This can fuel a view that educational literature cannot be applied to actual practise, resulting in a disregard for such literature. This includes the avoidance of constructivist pedagogies in contexts where they would be implementable, appropriate, and very valuable, with reasonable levels of effort and attainable levels of skill. Therefore, I suggest that everyone will benefit by an acknowledgement in the literature that instructivist pedagogies and a focus on so-called lower order thinking are more appropriate in the context of developing countries than the research performed in developed countries suggests. At the same time, it is important to pay some attention to higher order thinking skills and develop capacity in the implementation of constructivist pedagogies. It would be particularly helpful if concrete exemplars of effective constructivist, higher-order thinking approaches within the South African low-quintile school context could be provided to help teachers to move towards such practice. 
Most of the argument I offer in this article has been embedded within IPM, which seems particularly useful for guiding an understanding of learning and the challenges of teaching in the South African low-quintile school context. This would probably be the case for any context in which language barriers and low levels of prior knowledge and skill significantly reduce the size of working memory. In such cases, it seems more likely that motivation will come from success, even in some small task, than it would from the provision of a complex authentic context which adds cognitive load to the already severely taxed working memory. I propose that a minimum threshold of competence, and therefore of available working memory space, is needed before participatory learning models, such as situativity learning theory, become useful on a large scale in understanding learning and in guiding pedagogy in the South African low-quintile context.

\section{Conclusion}

The following lines of progression are central to the argument I make in this article: progression from a state of low to high language ability and prior skill and knowledge competence of learners; progression of school environments along what Johnson et al. (2000) liken to an ecological continuum; and progression of teachers through their four pedagogical stages. These three progressions could be seen as forming the axes of a three-dimensional representation within which any particular learning situation could be plotted. It seems reasonable to suspect that most practical learning situations would lie roughly equidistantly along each of these axes, and for such situations it is suggested that instructivist pedagogy should be used to a greater extent initially, with a progressively greater proportion of time and emphasis being given to constructivist pedagogy along these progressions. Currently, classrooms in South African low-quintile schools are situated near the beginning of each of these progressions, making acquiry models of learning and instructivist pedagogies more appropriate. This implies that the effectiveness of resources, such as the ones proposed in this article, lie in their ability to promote success at the point at which learners, teachers and school environments currently find themselves, while also moving them forward.

\section{References}

Anderson, L. W., \& Sosniak, L. A. (1994). Bloom's taxonomy. Chicago, IL: University of Chicago Press.

Ausubel, D., Novak, J., \& Hanesian, Y. (1986). Educational psychology: A cognitive view. New York, NY: Holt, Rinehart, \& Winston.

Bayat, A., Louw, W., \& Rena, R. (2014). The impact of socio-economic factors on the performance of selected high school learners in the Western Cape Province, South Africa. Journal of Human Ecology, 45(3), 183-196.

Beattie IV, V., Collins, B., \& McInnes, B. (1997). Deep and surface learning: A simple or simplistic dichotomy? Accounting Education, 6(1), 1-12. 
Beeby, C. (1966). The quality of education. Cambridge, MA: Harvard University Press.

Branson, N., Hofmeyr, C., \& Lam, D. (2014). Progress through school and the determinants of school dropout in South Africa. Development Southern Africa, 31(1), 106-126.

Burns, T.C., \& Ungerleider, C.S. (2003). Information and communication technologies in elementary and secondary education: State of the art review. International Journal of Education Policy, Research and Practice, 3(4), 27-53.

Carey, B. (2014). How we learn: The surprising truth about when, where and why it happens. London, UK: Pan Macmillan.

Cheng, A., Hitt, C., Kisida, B., \& Mills, J. N. (2017). "No excuses" Charter Schools: A metaanalysis of the experimental evidence on student achievement. Journal of School Choice, 11(2), 209-238.

Chisholm, L. (2000). A South African curriculum for the 21st century. Report of the Review Committee on Curriculum 2005. Retrieved from http://citeseerx.ist.psu.edu/viewdoc/download?doi=10.1.1.361.5200\&rep=rep1\&type= pdf

Chisholm, L., Motala, S., \& Vally, S. (2003). South African education policy review: 19932000. Johannesburg, South Africa: Heinemann.

Christie, P., Butler, D., \& Potterton, M. (2007). Schools that work. Report of the Ministerial Committee, Pretoria: Government Printer.

Chukharev-Hudilainen, E., \& Klepikova, T. A. (2016). The effectiveness of computer-based spaced repetition in foreign language vocabulary instruction: A double-blind study. CALICO Journal, 33(3), 334-354.

Cooper, A. (2015). We need to talk about learning: Dialogue and learning amongst South African youth. In J. Wyn \& H. Cahill (Eds.), Handbook of Children and Youth Studies (pp. 419-432). London, UK: Springer.

Cronjé, J. (2007). Towards integrating objectivism and constructivism in instructional design and learning sciences. Educational Technology Research and Development, 54(4), 387-416.

De Villiers, M. (2007). The six C's framework for e-learning. In N. Buzetto-More (Ed.), Advanced principles of effective e-learning (pp. 1-25). Santa Rosa, CA: Informing Science Press.

Department of Education. (2003). National Curriculum Statement Grades 10-12 (General). Retrieved from www.education.gov.za.

Fletcher, J. (2009). From behaviorism to constructivism: A philosophical journey from drill and practice to situated learning. In S. Tobias \& T. M. Duffy (Eds.), Constructivist instruction: Success or failure? (pp. 242-263). New York, NY: Routledge. 
Graven, M. H. (2014). Poverty, inequality and mathematics performance: The case of South Africa's post-apartheid context. ZDM, 46(7), 1039-1049.

Guthrie, G. (2017). The failure of progressive paradigm reversal. Compare: A Journal of Comparative and International Education, 47(1), 62-76.

Guthrie, G. (2018). Classroom change in developing countries: From progressive cage to formalistic frame. London, UK: Routledge.

Hoadley, U. (2018). Pedagogy in poverty: Lessons from twenty years of curriculum reform in South Africa. New York, NY: Routledge.

Hugo, W., \& Wedekind, V. (2013). Six failures of the pedagogic imagination: Bernstein, Beeby and the search for the optimal pedagogy for the poor. South African Review of Education, 19(1), 139-157.

Jansen, J., \& Blank, M. (2014). How to fix South Africa's schools: Lessons from schools that work. Johannesburg, South Africa: Bookstorm.

Johnson, S., Monk, M., \& Hodges, M. (2000). Teacher development and change in South Africa: A critique of the appropriateness of transfer of northern/western practice. Compare, 30(2), 179-192.

Jongsma, E. (1971). The Cloze Procedure as a teaching technique. Newark, DE: The International Reading Association.

Klahr, D. (2009). "To every thing there is a season, and a time to every purpose under the heavens" What about direct instruction? In S. Tobias \& T. M. Duffy (Eds.), Constructivist instruction: Success or failure? (pp. 291-310). New York, NY: Routledge.

Knight, S. L., Lloyd, G. M., Arbaugh, F., Gamson, D., McDonald, S. P., Nolan, J., \& Whitney, A. E. (2015). Reconceptualizing teacher quality to inform preservice and inservice professional development. Journal of Teacher Education, 66(2), 105-108.

Konicek-Moran, R., \& Keeley, P. (2015). Teaching for conceptual understanding in science. Arlington, TX: NSTA Press, National Science Teachers Association.

Lattimer, H. (2015). Translating theory into practice: Making meaning of learner centered education frameworks for classroom-based practitioners. International Journal of Educational Development, 45, 65-76.

Lidbury, B., \& Zhang, F. (2008). Comprehension of scientific language as a strategy to enhance learning and engagement for molecular biology students. Australian Biochemist, 39(3), 10-13.

Malcolm, C., Keane, M., Hoohlo, L., Kgaka, M., \& Ovens, J. (2000). Why some "disadvantaged" schools succeed in mathematics and science: A study of "feeder" schools. Pretoria, South Africa: Department of Education. 
Mattar, J. (2018). El constructivismo y el conectivismo en tecnología educativa: El aprendizaje activo, situado, auténtico, experiencial y anclado [Constructivism and connectivism in education technology: Active, situated, authentic, experiential, and anchored learning]. Revista Iberoamericana de Educación a Distancia, 21(2). Retrieved from http://revistas.uned.es/index.php/ried/article/view/20055

Mayer, R. E. (2009). Multimedia learning (2nd ed.). Santa Barbara, CA: Oxford University Press.

McKenney, S. (2013). Designing and researching technology-enhanced learning for the zone of proximal implementation. Research in learning technology, 21, 17374. Retrieved from https://journal.alt.ac.uk/index.php/rlt/article/view/1279

Muldner, K., Burleson, W., Van de Sande, B., \& VanLehn, K. (2011). An analysis of students' gaming behaviors in an intelligent tutoring system: Predictors and impacts. User modeling and User-adapted Interaction, 21(1-2), 99-135.

Niederhauser, D. S., \& Stoddart, T. (2001). Teachers' instructional perspectives and use of educational software. Teaching and Teacher Education, 17(1), 15-31.

O'Toole, J. M., \& Schefter, M. (2008). Patterns of student difficulty with science text in undergraduate Biology courses. International Journal of Learning, 15(1), 133-148.

Pretorius, E. J. (2015). Failure to launch: Matching language policy with literacy accomplishment in South African schools. International Journal of the Sociology of Language, 2015(234), 47-76.

Pretorius, E. J., \& Spaull, N. (2016). Exploring relationships between oral reading fluency and reading comprehension amongst English second language readers in South Africa. Reading and Writing, 29(7), 1449-1471.

Resnick, L. B. (1987). Education and learning to think. Washington, DC: National Academy Press.

Savery, J. R. (2006). Overview of problem-based learning: Definitions and distinctions. The Interdisciplinary Journal of Problem-based Learning, 1(1), 9-20.

Schweisfurth, M. (2011). Learner-centred education in developing country contexts: From solution to problem? International Journal of Educational Development, 31(5), 425432.

Schweisfurth, M. (2013). Learner-centred education in international perspective. Journal of International and Comparative Education, 2(1), 1-8.

Seddon, G. M. (1978). The properties of Bloom's taxonomy of educational objectives for the cognitive domain. Review of Educational Research, 48(2), 303-323.

Spaull, N. (2013). Poverty \& privilege: Primary school inequality in South Africa. International Journal of Educational Development, 33(5), 436-447. 
Spaull, N., \& Kotze, J. (2015). Starting behind and staying behind in South Africa: The case of insurmountable learning deficits in mathematics. International Journal of Educational Development, 41, 13-24.

Stott, A. E. (2008). Promotion of critical thinking in school physical science (Unpublished doctoral dissertation). University of KwaZulu-Natal, Durban.

Stott, A. E. (2017). The effectiveness of a conceptually focused out-of-class intervention on promoting learning of electricity by township learners. African Journal of Research in Mathematics, Science and Technology Education, 21(3), 304-315. doi: 10.1080/18117295.2017.1371981

Stott, A. E. (2018). Physical sciences teachers' beliefs about technology for teaching and factors influencing their uptake of a specific technology. Paper presented at the 26th Conference of the Southern African Association for Research in Mathematics, Science and Technology Education (SAARMSTE), Gaborone, Botswana.

Stott, A. E., \& Hobden, P. A. (2008). Balancing numerical practice and conceptual explanations in a crowded physical science curriculum. Paper presented at the 16th Annual Conference of the Southern African Association for Research in Mathematics, Science and Technology Education, Maseru, Lesotho.

Sweller, J. (2009). What human cognitive architecture tells us about constructivism. In S. T. T. M. Duffy (Ed.), Constructivist Instruction: Success or Failure? (pp. 127-143). New York, NY: Routledge.

Tabulawa, R. (2003). International aid agencies, learner-centred pedagogy and political democratisation: A critique. Comparative Education, 39(1), 7-26.

Tabulawa, R. (2013). Teaching and learning in context: Why pedagogical reforms fail in Sub-Saharan Africa. Dakar, Senegal: Council for the Development of Social Science Research in Africa.

Tobias, S. (2009). An eclectic appraisal of the success or failure of constructivist instruction. In S. Tobias \& T. M. Duffy (Eds.), Constructivist instruction: Success or failure? (pp. 335-350). New York, NY: Routledge.

Todd, A., \& Mason, M. (2005). Enhancing learning in South African schools: Strategies beyond outcomes-based education. International Journal of Educational Development, 25(3), 221-235.

Van der Berg, S., Spaull, N., Wills, G., Gustafsson, M., \& Kotzé, J. (2016). Identifying binding constraints in education. Stellenbosch, South Africa: Department of Economics, University of Stellenbosch.

Wellington, J., \& Osborne, J. (2001). Language and literacy in science education. Buckingham, UK: Open University Press.

Wenger, E. (1999). Communities of practice: Learning, meaning and identity. Cambridge, UK: Cambridge University Press. 
Wise, A. F., \& O'Neill, K. (2009). Beyond more versus less: A reframing of the debate on instructional guidance. In S. Tobias \& T. M. Duffy (Eds.), Constructivist Instruction: Success or Failure? (pp. 82-105). New York, NY: Routledge.

Zipin, L. (2013). Starting from pedagogical zero in “developing” contexts? Let's re-imagine! A response to Hugo and Wedekind. Southern African Review of Education, 19(1), $158-166$. 